\title{
PENGARUH ATMOSFER TOKO DAN DAYA TARIK PROMOSI PENJUALAN TERHADAP KEPUASAN PELANGGAN DAN NIAT BELI ULANG (DI MATAHARI MALL BALI GALERIA KUTA)
}

\author{
I Putu Gede Manik Kartika Yudha ${ }^{1}$ \\ Ni Wayan Sri Suprapti ${ }^{2}$ \\ ${ }^{1,2}$ Fakultas Ekonomi dan Bisnis Universitas Udayana, Bali, Indonesia \\ Email : manik.yudha@gmail.com
}

\begin{abstract}
ABSTRAK
Penelitian ini bertujuan untuk mengetahui pengaruh atmosfer toko dan daya tarik promosi penjualan terhadap kepuasan pelanggan dan niat beli ulang (di Matahari Mall Bali Galeria Kuta). Populasi dalam penelitian ini adalah seluruh pelanggan yang pernah melakukan pembelian minimal tiga kali (3x) di Matahari Department Store Mall Bali Galeria. Responden penelitian sebanyak 125 responden adalah pelanggan Matahari Mall Bali Galeria yang diambil dengan menggunakan purposive sampling. Data dianalisis dengan statistik deskriptif berupa rata-rata hitung dan statistik inferensial yaitu Partial Least Squares (PLS). Hasil penelitian menunjukkan bahwa (1) atmosfer toko berpengaruh positif dan signifikan terhadap kepuasan pelanggan, (2) atmosfer toko berpengaruh positif dan signifikan terhadap niat beli ulang, (3) daya tarik promosi penjualan berpengaruh positif dan signifikan terhadap kepuasan pelanggan, (4) daya tarik promosi penjualan berpengaruh positif dan signifikan terhadap niat beli ulang, dan (5) kepuasan pelanggan berpengaruh positif dan signifikan terhadap niat beli ulang.
\end{abstract}

Kata kunci : atmosfer toko, daya tarik promosi penjualan, kepuasan pelanggan, niat beli ulang.

\begin{abstract}
This study aims to determine the influence of store atmosphere and sales promotion appeal to customer satisfaction and re-purchase intention (in Matahari Mall Bali Galeria Kuta). The population in this study is all customers who have made purchases at least three times $(3 \mathrm{x})$ at Matahari Department Store Mall Bali Galeria. Respondents as many as 125 customers are visitors of Matahari Mall Bali Galeria taken by using purposive sampling. The data were analyzed by descriptive statistic in the mean of count and inferential statistic namely Partial Least Squares (PLS). The result of the research shows that (1) store atmosphere has positive and significant effect to customer satisfaction, (2) store atmosphere has positive and significant effect to repurchase intention, (3) sales promotion appeal positively and significantly to customer satisfaction, (4) the pull of sales promotion has a positive and significant impact on repurchase intention, and (5) customer satisfaction has a positive and significant impact on repurchase intention.
\end{abstract}

Key words : Store atmosphere, sales promotion appeal, customer satisfaction, re-purchase intention. 
I Putu Gede Manik Kartika Yudha., Ni Wayan Sri Suprapti. Pengaruh Atmosfer Toko...

\section{PENDAHULUAN}

Dewasa ini pertumbuhan daya beli pelanggan semakin meningkat yang diiringi dengan meningkatnya perkembangan usaha dalam bidang ritel. Berkembangnya pusat ritel, menyebabkan banyak toko yang berkonsep swalayan seperti minimarket, supermarket, dan hypermarket di berkembang di sejumlah daerah perkotaan. Bisnis ritel saat ini terus bermunculan di berbagai daerah seperti kabupaten dan desa-desa sperti supermarket dan minimarket, yang mana pemukiman banyak di daerah tersebut.

Kepuasan pelanggan dinilai menjadi sebuah hal yang penting dalam meningkatkan keuntungan. Kepuasan pelanggan merupakan sebuah hal yang penting bagi perusahaan, yang mana bertujuan untuk menjalin hubungan baik jangka panjang dengan pelanggan, dan pada akhirnya pelanggan bersedia melakukan pembelian ulang. Giese dan Cote (2000) menunjukkan bahwa kepuasan sebenarnya adalah reaksi emosional yang terkait dengan harapan produk dan pengalaman sebelumnya. Kepuasan terjadi setelah mengkonsumsi produk atau jasa dan memiliki karakter kumulatif.

Kepuasan juga mempengaruhi pelanggan untuk merekomendasikan department store (toko) dan juga melakukan pembelian ulang, namun tidak berdampak langsung pada loyalitas pelanggan. Kunci untuk menghasilkan loyalitas adalah membuat pelanggan merekomendasikan toko kepada orang lain. Selain itu, pelanggan cenderung merekomendasikan department store (toko) pada saat pelanggan merasa puas dan memiliki sikap relatif baik terhadap toko itu (Sivadas dan Baker-Prewitt, 2000). 
Seiring pasar ritel yang menjadi semakin kompetitif, retailer terus mencari penawaran yang berbeda untuk memasarkan ritel mereka. Salah satu cara yang bisa mereka bedakan adalah dengan menyediakan lingkungan belanja yang disesuaikan dengan kebutuhan pelanggan, tidak hanya dalam hal barang dagangan, kenyamanan dan harga tetapi juga dalam memberikan suasana belanja yang menyenangkan dan juga menarik.

Faktor lingkungan seperti musik, pencahayaan, warna, dan aroma membantu menciptakan kesan sensoris yang mendasari pengalaman belanja yang menyenangkan (Pine dan Gilmore, 1998). Oleh karena itu, menemukan desain atmosfer yang unik dan efektif merupakan perhatian utama bagi pengecer yang ingin menciptakan dan mempertahankan keunggulan kompetitif. Pengalaman yang menyenangkan di sebuah toko yang membuat pelanggan menghabiskan lebih banyak waktu di toko dan menghabiskan lebih banyak uang daripada yang semula direncanakan (Donovan et al., 1994).

Perusahaan selalu menargetkan kesuksesan jangka panjang. Agar sukses dalam jangka panjang, mereka harus memperhatikan pembelian ulang dari para pelanggan. Hal yang paling penting dari niat beli ulang pelanggan adalah dengan menawarkan kualitas layanan terbaik kepada pelanggan. Tsai, Huang, Jaw dan Chen (2006) menyatakan bahwa pembelian kembali telah menunjukkan bahwa pelanggan yang puas cenderung melanjutkan hubungan mereka dengan perusahaan daripada yang tidak puas.

Perusahaan perlu menerapkan strategi promosi untuk meningkatkan niat beli ulang dari produk yang dijual, salah satu strategi promosi yang dapat di terapkan 
I Putu Gede Manik Kartika Yudha., Ni Wayan Sri Suprapti. Pengaruh Atmosfer Toko...

adalah promosi penjualan. Brassington and Pettitt (2000), daya tarik promosi penjualan adalah tehnik pemasaran yang dirancang dalam sebuah bentuk pemasaran yang bersifat strategis untuk menambahkan nilai tambah pada produk atau layanan melebihi dan di atas penawaran 'normal' untuk mencapai tujuan penjualan dan pemasaran yang spesifik. Nilai tambah ini mungkin merupakan taktik jangka pendek atau mungkin merupakan bagian dari program pengembangan waralaba jangka panjang. "

Promosi penjualan digunakan sebagai cara untuk menarik perhatian pada bisnis Anda atau memberikan insentif bagi pelanggan untuk melakukan tindakan yang diinginkan. Promosi penjualan biasanya berlangsung selama jangka waktu tertentu dan dirancang untuk mencapai tujuan yang ditetapkan seperti membantu meluncurkan bisnis baru atau menarik pelanggan dari pesaing. Berbagai bentuk promosi penjualan adalah : diskon, bonus pack (beli 2 gratis 1), pengujian gratis, premium, hadiah, kartu keanggotaan, kupon belanja, percobaan produk gratis (Alimpic, 2014).

Tujuan utama dari promosi penjualan adalah untuk menghabiskan stok lama, membuat pembeli potensial mencoba produk, meningkatkan pembelian tetap berulang pelanggan, menganggu peluncuran produk pesaing, memberikan daya tarik berupa manfaat jangka panjang, menciptakan kesadaran pelanggan dari sebuah produk, menciptakan daya tarik produk.

Matahari Department Store merupakan perusahaan jaringan ritel yang menjual kebutuhan rumah tangga dan fashion terkini dan berkualitas tinggi, untuk masyarakat yang berpenghasilan menengah ke bawah dengan harga yang 
terjangkau. Matahari Mall Bali Galeria juga menyediakan berbagai jenis fasilitas pendukung kegiatan belanja. Fasilitas-fasilitas ini disediakan oleh perusahaan dengan tujuan memfasilitasi pelanggan agar lebih mudah dalam memenuhi kebutuhannya. Fasilitas-fasilitas fisik yang disediakan antara lain berupa eskalator, area parkir, toilet, serta alat pembayaran elektronik tanpa menggunakan uang tunai. Jam operasional Matahari Mall Bali Galeria berlangsung dari pagi hingga malam hari. Pihak manajemen Matahari Mall Bali Galeria senantiasa menyediakan karyawan yang ramah dan mampu melayani pelanggan saat berbelanja di dalam gerai.

Penelitian ini bertujuan untuk menjelaskan : (1) pengaruhatmosfer toko terhadap kepuasan pelanggan Matahari Mall Bali Galeria, (2) pengaruh atmosfer toko terhadap niat beli ulang pelanggan Matahari Mall Bali Galeria, (3) pengaruh daya tarik promosi penjualan terhadap kepuasan pelanggan Matahari Mall Bali Galeria, (4) pengaruh daya tarik promosi penjualan terhadap niat beli ulang pelanggan Matahari Mall Bali Galeria, (5) pengaruh kepuasanpelanggan terhadap niat beli ulang pelanggan Matahari Mall Bali Galeria.

\section{Tinjauan Pustaka}

Atmosfer toko merupakan faktor penting dalam pembentukan citra toko dan melibatkan atribut toko yang nyata dan tidak berwujud. Penelitian empiris yang ada menunjukkan bahwa persepsi atmosfer toko sangat berkorelasi dengan niat pelanggan untuk mempengaruhi toko tersebut (Grewal et al., 2003).

Baker et al., (1994), elemen toko dapat dikategorikan menjadi tiga kelompok yang berbeda: faktor ambien, faktor desain, dan faktor sosial. Faktor 
I Putu Gede Manik Kartika Yudha., Ni Wayan Sri Suprapti. Pengaruh Atmosfer Toko...

lingkungan adalah kondisi latar belakang nonvisual seperti musik latar, suhu, pencahayaan, dan aroma (Ward et al., 2007). Sebuah toko yang memiliki pencahayaan yang redup dan memainkan musik klasik dianggap memiliki citra toko yang lebih bergengsi, sedangkan toko yang memiliki pencahayaan terang dan memainkan musik papan atas dianggap menjual produk lebih murah (Gardner dan Siomkos, 1985). Faktor desain adalah elemen visual dari atmosfer toko, yang dapat bersifat fungsional atau estetis tergantung pada tujuannya (Baker et al., 1994). Tata letak, kenyamanan, dan privasi dianggap sebagai elemen fungsional toko, sementara arsitektur, warna, bahan, dan gaya dianggap sebagai elemen toko yang bersifat estetika. Faktor sosial berhubungan dengan orang-orang di lingkungan toko, termasuk jumlah, jenis, dan perilaku pelanggan dan tenaga penjualan lainnya. Beberapa penelitian menunjukkan bahwa lingkungan yang ramai memiliki pengaruh persepsi negatif dari pelanggan terhadap sebuah toko (Eroglu dan Machleit, 1990).

Promosi penjualan adalah perangkat dan teknik pemasaran yang digunakan untuk membuat barang dan jasa lebih menarik dengan memberikan beberapa keuntungan tambahan, baik secara tunai maupun barang, atau harapan akan manfaat (Boddewyn dan Leardi, 1989).

Upaya promosi penjualan bisa menghasilkan keuntungan maksimal melalui peningkatan penjualan dengan menggunakan berbagai teknik pemasaran seperti penjualan pribadi, periklanan, events, window layout, dan budaya. Hal ini mungkin terjadi dalam bentuk pengiriman direct-email, katalog, perdagangan dan peragaan busana, pelatihan gratis, kupon, demo, pengurangan harga, hadiah gratis, 
dan kontes. Tujuan promosi penjualan adalah untuk menarik pelanggan potensial untuk meningkatkan margin keuntungan dalam penjualan instan. (Hanssens et al., 2001) mencatat bahwa promosi penjualan berpengaruh langsung terhadap volume penjualan bisnis. Dengan cara yang sama, Ailawadi dan Neslin (1998) telah mengemukakan bahwa promosi penjualan dapat mempengaruhi perilaku pembelian konsumen dan memotivasi mereka untuk melakukan pembelian lebih cepat dan lebih besar. Pertumbuhan volume penjualan ini pada akhirnya dapat menyebabkan kenaikan margin keuntungan.

Kepuasan pelanggan didefinisikan sebagai evaluasi keseluruhan berdasarkan total pengalaman pembelian dan konsumsi pelanggan dengan barang atau layanan dari waktu ke waktu (Anderson, Fornell, dan Mazvancheryl 2004; Fornell 1992). Kepuasan pelanggan adalah istilah pemasaran yang mengukur bagaimana produk atau layanan yang diberikan oleh perusahaan memenuhi atau melampaui harapan pelanggan. Kepuasan pelanggan sekarang dianggap sebagai strategi tingkat korporat (Rust \& Zahorik, 1993). Penelitian menunjukkan bahwa kepuasan pelanggan adalah dasar dan sumber keberhasilan suatu organisasi. Keberhasilan strategi perusahaan bergantung pada kemampuan perusahaan untuk memenuhi janjinya kepada konsumen, yang pada gilirannya mengarah pada pembentukan hubungan jangka panjang dan menguntungkan (Carpenter dan Fairhurst 2005). 
I Putu Gede Manik Kartika Yudha., Ni Wayan Sri Suprapti. Pengaruh Atmosfer Toko...

Kepuasan pelanggan terjadi ketika konsumen merasa puas dengan kualitas pelayanan. Menurut Ciavolino \& Dahlgaard (2007) hal tersebut adalah:

1. Layanan Tambahan

Layanan tambahan pada dasarnya penting dalam bisnis ritel dan berperan dalam menentukan kepuasan pelanggan melalui penciptaan kenyamanan.

2. Kualitas Produk

Kinerja yang mengacu pada karakteristik dan kesesuaian operasi utama produk yang digambarkan sebagai sejauh mana suatu produk akan beroperasi dengan benar selama jangka waktu tertentu dalam kondisi yang dinyatakan menggunakan Reliability.

3. Nilai Uang

Nilai untuk uang adalah tingkat kualitas yang dirasakan relatif terhadap harga yang harus dibayar untuk produk atau jasa. Nilai uang didasarkan pada harga produk yang kompetitif, diskon diberikan kepada pelanggan, dan promosi.

4. Fasilitas

Fasilitas toko sebagai jumlah elemen yang berkontribusi pada suasana belanja yang menyenangkan seperti tata letak atau gang toko yang memudahkan untuk bergerak, kebersihan dan menampilkan produk yang bagus.

Kunci untuk menghasilkan loyalitas adalah membuat pelanggan merekomendasikan toko kepada orang lain. Selain itu, pelanggan cenderung 
merekomendasikan department store (toko) pada saat pelanggan merasa puas dan memiliki sikap relatif baik terhadap toko itu (Sivadas dan Baker-Prewitt, 2000).

Kepuasan secara umum dieksplorasi sebagai kepuasan pelanggan total dan dalam ekspektasi pendekatan dengan produk atau layanan yang dirasakan, yaitu sebuah produk ideal dibandingkan dengan yang dibeli (Johnson et al., 1995). Demikian pula, Giese dan Cote (2000) menunjukkan bahwa kepuasan sebenarnya adalah reaksi emosional yang terkait dengan harapan produk dan pengalaman sebelumnya.

Niat beli ulang (repurchase intention) merupakan suatu komitmen pelanggan yang terbentuk setelah pelanggan melakukan pembelian suatu produk atau jasa. Komitmen ini timbul karena kesan positif pelanggan terhadap suatu merek, dan pelanggan merasa puas terhadap pembelian tersebut (Hicks et al, 2005). Butcher (2005) berpendapat bahwa minat pelanggan untuk membeli ulang adalah salah satu ukuran dari keberhasilan dari suatu perusahaan, terutama perusahaan jasa. Niat beli ulang ditempuh dengan cara membangun dan mengelola hubungan dengan pelanggan melalui penawaran dengan terus memberikan nilai dan meningkatkan kepuasan pelanggan. Oleh karena itu, untuk meningkatkan niat beli ulang pelanggan, perusahaan harus berfokus tidak hanya pada pembelian berulang-ulang melalui berbagai kegiatan promosi, namun cobalah untuk memancing komitmen dan sikap pelanggan terhadap perusahaan mereka.

Hawkins et al. (2007) menyatakan bahwa pelanggan yang melakukan pembelian ulang berlanjut untuk terus membeli merek yang sama walaupun tidak 
I Putu Gede Manik Kartika Yudha., Ni Wayan Sri Suprapti. Pengaruh Atmosfer Toko...

memiliki keterikatan emosional terhadap merek tersebut. Pelanggan yang memiliki komitmen pada umumnya lebih mudah menerima perluasan lini produk baru yang ditawarkan oleh perusahaantersebut. Kesesuaian antara performa dari produk atau jasa yang ditawarkan akan memberikan kepuasan bagi pelanggan dan menghasilkan minat pelanggan untuk menggunakannya kembali di waktu yang akan datang. Pelanggan yang merasa puas dan menjadi pelanggan yang berkomitmenjuga dapat menjadi sumberrekomendasi positif (positive word-of-mouth) bagi pelanggan lainnya terhadap merek tersebut. Zeithaml et al. (1996) mengemukakan terdapat dua jenis niat beli ulang, yaitu (1) niat untuk membeli kembali dan (2), maksud untuk terlibat dalam kata positif dari mulut ke mulut dan merekomendasikannya.

\section{Hipotesis Penelitian}

Pudjianto et al, (2015) mendapatkan hasil bahwa variabel atmosfer toko berpengaruh positif terhadap customer satisfaction pelanggan. Menurut Hersanti (2012) atmosfer toko berpengaruh positif terhadap kepuasanpelanggan.

Nizar (2016) menyatakan bahwa store atmosphere memiliki efek yang signifikan terhadap customer satisfaction. Pengaruh atmosfer toko terhadap kepuasan pelanggan ditunjukkan oleh koefisien beta yang masing-masing sebesar 0,237, nilai t hitung 2,751 dan probabilitas sebesar 0,007 ( $\mathrm{p}<0,05)$, maka H0 ditolak. Dengan demikian, dapat dinyatakan suasanatoko berpengaruh secara positif dan signifikan terhadap kepuasan pelanggan diterima.

H1: Atmosfer toko berpengaruh secara positif dan signifikan terhadap kepuasan pelanggan 
Wandira (2016) menyatakan atmosfer toko berpengaruh positif terhadap niat beli ulang pelanggan dengan kepuasan kelanggan sebagai variabel intervening. menemukan bahwa dari hasil regresi diperoleh koefisien path untuk variabel atmosfer toko adalah sebesar 0,881. Hubungan antara kedua variabel ini signifikan karena nilai signifikansi 0.000 atau kurang dari $\alpha$ yang dipakai dalam penelitian ini yaitu 0,005. Hipotesis yang menguji pengaruh langsung antara atmosfer toko terhadap minat pembelian ulang pelanggan dapat diterima karena nilai t-hitung adalah 12.227 di mana nilai tersebut lebih besar dari t-tabel yang digunakan dalam penelitian ini 1,98217. Berdasarkan penjelasan tersebut maka dapat dikatakan bahwa terdapat pengaruh langsung yang positif siginifikan antara variabel atmosfer toko terhadap variabel minat pembelian ulang pelanggan.

Anja et al, (2014) menyatakan bahwa atmosfer toko eceran grosir pada berbagai elemen berpengaruh positif terhadap niat membeli kembali tergantung pada jenis kelamin.

H2: Atmosfer toko berpengaruh secara positif dan signifikan terhadap niat beli ulang

Diyanthini dan Seminari (2014) menyatakan bahwa variabel promosi penjualan berpengaruh secara positif dan signifikan terhadap kepuasan nasabah. Tjahjaningsih (2013) menemukan bahwa promosi berpengaruh positif dan signifikan terhadap kepuasan pelanggan. Promosi berpengaruh positif dengan beta $=0,333$ dan signifikan terhadap 
I Putu Gede Manik Kartika Yudha., Ni Wayan Sri Suprapti. Pengaruh Atmosfer Toko...

kepuasan pelanggan dengan $(n=0,00<0,05)$. Hal ini menunjukkan bahwa semakin tinggi promosi, maka akan semakin tinggi pula kepuasanpelanggan.

H3 : Promosi Penjualan berpengaruh secara positif dan signifikan terhadap kepuasan pelanggan

Neha et al, (2013) menyatakan bahwa di antara berbagai alat promosi penjualan, seperti : penawaran, premium dan kontes berpengaruh positif terhadap keputusan pembelian konsumen, dan dapat disimpulkan bahwa alat promosi penjualan berperan penting dalam keputusan pembelian konsumen. Amanda et al, (2015) menyatakan bahwa promosi penjualan memiliki pengaruh yang signifikan terhadap minat beli.

H4: Daya tarik promosi penjualan berpengaruh secara positif dan signifikan terhadap niat beli ulang.

Asakdiyah (2005) menyatakan bahwa kepuasan pelanggan berpengaruh positif terhadap niat beli. Saidani et al, (2012) menemukan bahwa variabel kepuasan pelanggan berpengaruh positif terhadap niat beli ulang pelanggan. Nilai koefisien estimasi path untuk masing-masing variabel adalah 0,$54 ; 0,20$; dan 0,20. Keempat variabel ini mampu menjelaskan keragaman nilai yang terjadi pada Minat Beli Ulang Konsumen sebesar 62 persen. Sedangkan sisanya 38 persen dijelaskan oleh variabel-variabel lain yang tidak dimasukkan ke dalam model. Berdasarkan hasil analisis penelitian, menunjukan bahwa adanya pengaruh yang signifikan antara variabel kepuasan konsumen terhadap minat beli ulang dengan nilai t-value 5,90.

H5: Kepuasan pelanggan berpengaruh secara positif dan signifikan terhadap niat beli ulang 
Berdasarkan kajian pustaka dan penelusuran terhadap sejumlah hasil-hasil studi empiris, maka disusun sebuah kerangka konseptual sebagai berikut :

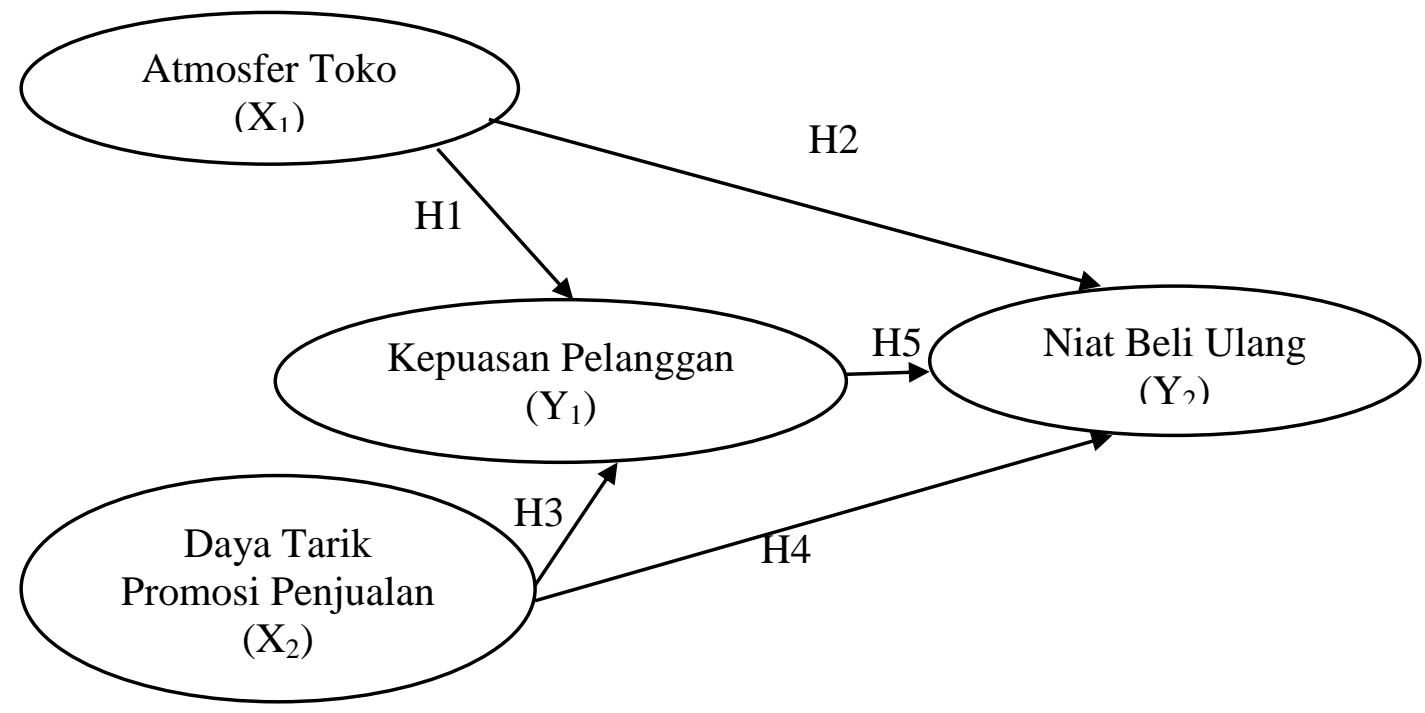

Gambar 1. Kerangka Konseptual Penelitian

\section{METODE PENELITIAN}

Lokasi penelitian ini dilakukan di Matahari Mall Bali Galeria karena memiliki segmentasi yang luas. Penelitian ini mengkaji dampak atau pengaruh yang ditimbulkan oleh pengaruh atmosfer toko dan daya tarik promosi penjualan terhadap kepuasan pelanggan dan niat beli ulang (di Matahari Mall Bali Galeria Kuta). Pada penelitian ini, variabel eksogen adalah presepsi pelanggan tentang atmosfer toko (X1) dan daya tarik promosi penjualan (X2) di Matahari Mall Bali Galeria, sedangkan variabel endogen ada dua yaitu kepuasan pelanggan (Y1) dan niat beli ulang (Y2) di Matahari Mall Bali Galeria. 
Tabel 4.1

Operasionalisasi Variabel

\begin{tabular}{|c|c|c|c|c|}
\hline \multirow{2}{*}{$\begin{array}{c}\text { Klasifikasi } \\
\text { Konstruk }\end{array}$} & \multirow[b]{2}{*}{ Konstruk } & \multirow[b]{2}{*}{ Simbol } & \multirow[b]{2}{*}{ Indikator } & \multirow[t]{2}{*}{ Sumber } \\
\hline & & & & \\
\hline \multirow{20}{*}{$\begin{array}{l}\text { Konstruk } \\
\text { Eksogen }\end{array}$} & Atmosfer & $\mathrm{X} .1 .1$ & Kebersihan & Berman and \\
\hline & Toko (X1) & X.1.2 & Musik & (2010) ; Hussain dan Ali \\
\hline & & X.1.3 & Aroma & (2015) ; Ryu dan Han \\
\hline & & X.1.4 & Suhu Ruangan & $(2010)$ \\
\hline & & X.1.5 & Pencahayaan & \\
\hline & & X.1.6 & Tata Warna & \\
\hline & & X.1.7 & Layout ruangan & \\
\hline & & X.1.8 & Display produk & \\
\hline & & X.1.9 & Kesesuaian space allocation & \\
\hline & Daya Tarik & $\mathrm{X} 2.1$ & Pemberian potongan harga (diskon) & Kotler and Keller (2009) \\
\hline & Promosi & $\mathrm{X} 2.2$ & Variasi jumlah potongan harga & ; Susilowati (2008) ; \\
\hline & Penjualan & $\mathrm{X} 2.3$ & Peragaan (display) produk & Buchari Alma (2004) ; \\
\hline & (X2) & $\mathrm{X} 2.4$ & Kupon (voucher) belanja & Neha dan Manoj (2013) \\
\hline & & $\mathrm{X} 2.5$ & Price Packs (beli 2 gratis 1) & ; Nagadeepa et al. \\
\hline & & $\mathrm{X} 2.6$ & Loyalty Program & $(2015)$ \\
\hline & & $\mathrm{X} 2.7$ & Pengujian produk & \\
\hline & Kepuasan & Y1.1 & Kepuasan secara umum & Kotler, $\quad$ (2009), \\
\hline & $\begin{array}{l}\text { Pelanggan } \\
\text { (Y1) }\end{array}$ & Y1.2 & Kepuasan terhadap fasilitas & $\begin{array}{l}\text { Gronholdth, et al. } \\
\text { (2000), Yohanes Yang }\end{array}$ \\
\hline & & $\mathrm{Y} 1.3$ & Kepuasan terhadap produk & et al. (2005), Chae et al. \\
\hline & & Y1.4 & Kepuasan terhadap layanan & (2002), Lin dan Wang \\
\hline \multirow[t]{5}{*}{$\begin{array}{l}\text { Konstruk } \\
\text { Endogen }\end{array}$} & & Y1.5 & Kepuasan terhadap nilai tambah & $\begin{array}{l}\text { (2006), Kirana Patni } \\
\text { (2011) }\end{array}$ \\
\hline & Niat Beli & $\mathrm{Y} 2.1$ & Kemauan untuk membeli kembali & Hawkins, et. al. (2007); \\
\hline & Ulang (Y2) & $\mathrm{Y} 2.2$ & $\begin{array}{l}\text { Pembelian ulang di masa yang akan } \\
\text { datang }\end{array}$ & $\begin{array}{lll}\text { Cronin et al. } & (2000), \\
\text { Wang et al. } & (2004),\end{array}$ \\
\hline & & Y2.3 & Pilihan utama pelanggan & Setyaningsih et. al. \\
\hline & & Y2.4 & Komitmen pelanggan & (2007) \\
\hline
\end{tabular}

Sumber : Data Diolah 2017

Konstruk yang diteliti dapat didefinisikan sebagai berikut :

1. Atmosfer Toko $\left(\mathrm{X}_{1}\right)$

X1.1 : Kebersihan yang tampak di Matahari Mall Bali Galeria

X1.2 : $\quad$ Musik yang diputar di Matahari Mall Bali Galeria

X1.3 : $\quad$ Aroma di Matahari Mall Bali Galeria

X1.4 : $\quad$ Suhu udara di Matahari Mall Bali Galeria

X1.5 : Pencahayaan atau tata cahaya di Matahari Mall Bali Galeria

X1.6 : $\quad$ Tata warnadi dalam Matahari Mall Bali Galeria 
X1.7 : $\quad$ Layout (tata ruang) di dalam Matahari Mall Bali Galeria

X1.8 : Display produk di dalam Matahari Mall Bali Galeria

X1.9 : Kesesuain antara lantai dan gerai Matahari Mall Bali Galeria

2. Promosi Penjualan $\left(\mathrm{X}_{2}\right)$

X2.1 : Pemberian potongan harga/diskon yaitu pemberian diskon pada produk tertentu yang dijual di Matahari Mall Bali Galeria

X2.2 : Variasi jumlah potongan harga yaitu jumlah potongan harga di Matahari Mall Bali Galeria yang bervariasi.

X2.3 : Peragaan (display) produk yaitu contoh produk yang dipajang atau ditampilkan di Matahari Mall Bali Galeria pada waktu, tempat dan situasi tertentu.

X2.4 : Kupon (voucher) belanja yaitu setiap pembelanjaan produk di Matahari Mall Bali Galeria dengan minimal jumlah nominal tertentu akan mendapatkan voucher belanja yang dapat digunakan untuk memotong nominal total pembelanjaan berikutnya.

X2.5 : Price pack yaitu satu kemasan yang dijual dengan pengurangan harga (seperti beli dua gratis satu)

X2.6 : Loyalty Program yaitu imbalan berlangganan di seluruh ritel Matahari berupa kartu keanggotaan (member card) 
I Putu Gede Manik Kartika Yudha., Ni Wayan Sri Suprapti. Pengaruh Atmosfer Toko...

X2.7 : Pengujian produk yaitu pelanggan Matahari Mall Bali Galeria dapat mencoba produk secara gratis sebelum pembelian dilakukan.

3. Kepuasan Pelanggan $\left(\mathrm{Y}_{1}\right)$

Y1.1 : Penilaian pelanggan secara umum mengenai kesesuaian antara harapan dan kinerja yang dirasakan dari Matahari Mall Bali Galeria

Y1.2 : Kepuasan pelanggan terhadap fasilitas yang disediakan di Matahari Mall Bali Galeria

Y1.3 : Kepuasan pelanggan terhadap produk yang ditawarkan di Matahari Mall Bali Galeria

Y1.4 : Kepuasan pelanggan terhadap pelayanan yang diberikan oleh karyawan Matahari Mall Bali Galeria

Y1.5 : Kepuasan pelanggan yang dirasakan tentang nilai tambah yang dirasakan di Matahari Mall Bali Galeria

4. Niat Beli Ulang $\left(\mathrm{Y}_{2}\right)$

Y2.1 : Kemauan pelanggan untuk melakukan pembelian ulang di Matahari Mall Bali Galeria.

Y2.2 : Persepsi pelanggan untuk melakukan pembelian ulang di masa yang akan datang.

Y2.3 : Persepsi pelanggan menjadikan Matahari Mall Bali Galeria sebagai pilihan utama saat berbelanja. 
Y2.4 : Persepsi pelanggan yang selalu berkomitmen untuk berbelanja kebutuhan pribadi atau keluarga di Matahari Mall Bali Galeria.

Jenis data yang digunakan dalam penelitian ini, dikategorikan kedalam data kualitatif dan data kuantitatif. Data kuantitatif dalam penelitian ini yaitu data yang diperoleh dari hasil penyebaran kuesioner yang diisi jawaban oleh responden. Adapun data kualitatif dalam penelitian ini antara lain data karakteristik responden seperti nama, jenis kelamin, status, pendidikan dan pekerjaan.

Populasi dalam penelitian ini adalah pelanggan yang berbelanja di Matahari Mall Bali Galeria. Sampel dalam penelitian ini berjumlah 125 responden yang di tentukan dengan menggunakan pertimbangan ukuran sampel 5 kalidarijumlah indikator yang ada (5 kali 25 indikator $)=125$ responden . Pertimbangan yang digunakan dalam memilih responden adalah pelanggan Matahari Department Store Mall Bali Galeria yang sudah pernah melakukan pembelian minimal tiga kali $(3 \mathrm{x})$. Pelanggan yang dipilih adalah pelanggan yang berbelanja dengan syarat minimal tamat SMA, dengan pertimbangan pelanggan memiliki pendidikan terkahir minimal SMA dapat memberikan pendapat yang rasional dan mampu untuk menjawab pertanyaan dalam kuesioner. Penelitian ini menggunakan kuisioner sebagai instrumen dalam mengumpulkan data dari responden. Kuisioner berisikan beberapa pernyataan mengenai identitas responden dan beberapa pernyataan mengenai variabel penelitian.

Data yang terkumpul dianalisis menggunakan statistikdeskriptif dan statistikinferensial. Analisis deskriptif dilakukan dengan maksud untuk 
I Putu Gede Manik Kartika Yudha., Ni Wayan Sri Suprapti. Pengaruh Atmosfer Toko...

mengetahuikarakteristik dan tanggapan respondenterhadap item-item pertanyaan dalam kuisioner, sedangkan statistik inferensial digunakanuntuk mengujihipotesis denganmenggunakan teknikanalisis SEM-PLS.

\section{HASIL PENELITIAN DAN PEMBAHASAN}

Responden berdasarkan usia didominasi oleh pelanggan berusia 21 sampai dengan 26 tahun sebesar 41,60\%, mengindikasikan bahwa pelanggan Matahari Mall Bali Galeria kebanyakan didominasi usia muda. Berdasarkan jenis kelamin, menunjukkan bahwa pelanggan yang berkunjung ke Matahari Mall Bali Galeria didominasi oleh perempuan sebesar $60,80 \%$. Hal ini menunjukkan tingginya jumlah perempuan yang datang ke Matahari Mall Bali Galeria. Berdasarkan dari latar belakang pendidikan, sebagian besar pelanggan Matahari Mall Bali Galeria mempunyai latar belakang SMA yaitu 70 orang (56\%). Selanjutnya dari latar belakang jenis pekerjaan maka sebagian besar pengunjung Matahari Mall Bali Galeria adalah pelajar/mahasiswa yaitu sebanyak 40 orang (32\%). Karakteristik responden diatas menentukan respon pelanggan dalam menjawab instrumen penelitian.

Tabel 2

Distribusi Jawaban Responden Terhadap Variabel Penelitian

\begin{tabular}{lcccccc}
\multicolumn{1}{c}{ Variabel/Indikator } & \multicolumn{3}{c}{ Distribusi Jawaban (Persen) } & Rata-rata \\
& STS & TS & N & S & SS \\
\hline Atmosfer Toko & & & & & & \\
Kebersihan & 3,2 & 4 & 32,8 & 28,8 & 31,2 & 2,83 \\
Musik & 4 & 4,8 & 32,8 & 28 & 30,4 & 2,86 \\
Aroma & 7,2 & 4 & 28 & 32 & 28,8 & 2,77 \\
Suhu Ruangan & 4,8 & 5,6 & 27,2 & 36 & 26,4 & 2,85 \\
Pencahayaan & 0,8 & 3,2 & 28,8 & 38,4 & 28,8 & 2,97 \\
Tata Warna & 3,2 & 3,2 & 32,8 & 32,8 & 28 & 2,87 \\
Layout Ruangan & 4,8 & 4 & 32,8 & 26,4 & 32 & 2,84 \\
Display Produk & 6,4 & 4 & 28,8 & 29,6 & 31,2 & 2,76 \\
Kesesuaian Space Allocation & 4,8 & 4 & 32 & 26,4 & 32,8 & 2,75 \\
Rata-rata Jawaban Variabel Atmosfer & & & & & & \\
Toko & 4,4 & 4,1 & 30,7 & 30,9 & 30,0 & 2,8
\end{tabular}


Daya Tarik Promosi Penjualan

Pemberian potongan harga (diskon)

Variasi jumlah potongan harga

Peragaan (display) produk

Kupon (voucher) belanja

Price Packs (beli 2 gratis 1)

Loyalty Program

Pengujian produk

Promosi Penjualan

Kepuasan Pelanggan

Kepuasan secara umum

Kepuasan terhadap fasilitas

Kepuasan terhadap produk

Kepuasan terhadap layanan

Kepuasan terhadap nilai tambah

Rata-Rata Jawaban Variabel Kepuasan

Pelanggan

Niat Beli Ulang

Kemauan untuk membeli kembali

Pembelian ulang di masa yang akan

datang

Pilihan utama pelanggan

Komitmen pelanggan

Rata-rata Jawaban Variabel Niat Beli

Ulang

Sumber : Data Primer 2017

$\begin{array}{llllll}3,2 & 4 & 29,6 & 30,4 & 32,8 & 2,86\end{array}$

$\begin{array}{llllll}5,6 & 4,8 & 28 & 32,8 & 28,8 & 2,7\end{array}$

$\begin{array}{llllll}6,4 & 2,4 & 33,6 & 28 & 29,6 & 2,73\end{array}$

$\begin{array}{llllll}4 & 4,8 & 31,2 & 27,2 & 32,8 & 2,74\end{array}$

$\begin{array}{llllll}4 & 3,2 & 33,6 & 28 & 31,2 & 2,95\end{array}$

$\begin{array}{llllll}1,6 & 5,6 & 36,8 & 22,4 & 33,6 & 2,98\end{array}$

$\begin{array}{llllll}3,2 & 5,6 & 34,4 & 31,2 & 25,6 & 2,94\end{array}$

$\begin{array}{llllll}4,0 & 4,3 & 32,5 & 28,6 & 30,6 & 2,8\end{array}$

$\begin{array}{llllll}2,4 & 4 & 37,6 & 30,4 & 25,6 & 2,9\end{array}$

$\begin{array}{llllll}4 & 8 & 28,8 & 25,6 & 33,6 & 2,94\end{array}$

$\begin{array}{llllll}1,6 & 3,2 & 34,4 & 29,6 & 31,2 & 3,02\end{array}$

$\begin{array}{llllll}1,6 & 1,6 & 38,4 & 28,8 & 29,6 & 3,45\end{array}$

$\begin{array}{llllll}2,4 & 4 & 35,2 & 25,6 & 32,8 & 3,46\end{array}$

$2,4 \quad 4,2 \quad 34,9 \quad 28,0 \quad 30,6 \quad 3,2$

$2,4 \quad 3,2 \quad 35,2 \quad 25,6 \quad 33,6 \quad 3,4$

$\begin{array}{llllll}0,8 & 3,2 & 40 & 26,4 & 29,6 & 3,38\end{array}$

$\begin{array}{llllll}0,8 & 3,2 & 34,4 & 32,8 & 28,8 & 3,38\end{array}$

$\begin{array}{llllll}0,8 & 10,4 & 32,8 & 23,2 & 32,8 & 3,42\end{array}$

$\begin{array}{llllll}1,2 & 5,0 & 35,6 & 27,0 & 31,2 & 3,4\end{array}$

Tabel 2 menunjukkan rata-rata skor jawaban responden untuk variabel atmosfer toko adalah sebesar 2,8. Ini artinya bahwa pelanggan Matahari Mall Bali Galeria merasakan atmosfer toko yang ada di Matahari Mall Bali Galeria sudah cukup baik, tetapi masih perlu diadakannya perbaikan terutama dari segi aroma toko yang belum maksimal, display produk yang masih dirasa kurang dalam hal menarik minat pelanggan, serta space allocation antara rak satu dan yang lainnya yang masih dirasa sempit. Untuk variabel daya tarik promosi penjualan respon pelanggan Matahari Mall Bali Galeria cukup tertarik dengan promosi yang dilakukan oleh Matahari Mall Bali Galeria. Ini terlihat dari rata-rata skor variabel daya tarik promosi penjualan sebesar 2,8. Pihak manajemen Matahari Mall Bali Galeria sebaiknya perlu melakukan inovasi dalam melakukan promosi penjualan agar pelanggan lebih tertarik dengan promosi-promosi yang ditawarkan oleh Matahari Mall Bali Galeria . 
I Putu Gede Manik Kartika Yudha., Ni Wayan Sri Suprapti. Pengaruh Atmosfer Toko...

Dari sisi kepuasan pelanggan secara keseluruhan, pelanggan sudah merasa cukup puas terhadap seluruh fasilitas yang dimiliki Matahari Mall Bali Galeria, hal ini terlihat dari rata-rata skor jawaban responden tentang kepuasan pelanggan sebesar 3,2. Namun pihak manajemen Matahari Mall Bali Galeria masih perlu meningkatkan pelayanan terutama pada fasililitas-fasilitas umum seperti wifi, dan toilet, karena indikator ini masih dianggap belum maksimal oleh pelanggan.

Pelanggan Matahari Mall Bali Galeria memiliki niat beli ulang yang tinggi, ini terlihat dari jumlah skor jawaban responden 3,4. Hal tersebut mengindikasikan bahwa pelanggan Matahari Mall Bali Galeria memiliki niat yang tinggi untuk melakukan pembelian ulang di Matahari Mall Bali Galeria. Untuk itulah maka pihak manajemen diharapkan mampu mempertahankan indikator-indikator yang sudah dianggap baik oleh pelanggan dan meningkatkan indikator-indikator yang masih dianggap kurang oleh pelanggan.

Terdapat tiga kriteria dalam pengujian outer model pada PLS, yaitu menggunakan convergent validity, discriminant validity, dan composite reliability.

Tabel 3 menunjukkan bahwa indikator kebersihan, musik, aroma, suhu ruangan, pencahayaan, tata warna, layout ruangan, display produk dan kesesuaian floor dan space allocation mempunyai outer loading lebih besar dari 0,5. Indikator aroma adalah indikator terkuat dari variabel atmosfer toko karena mempunyai outer loading paling besar $(0,854)$. 
Tabel 3

Uji Validitas dan Reliabilitas

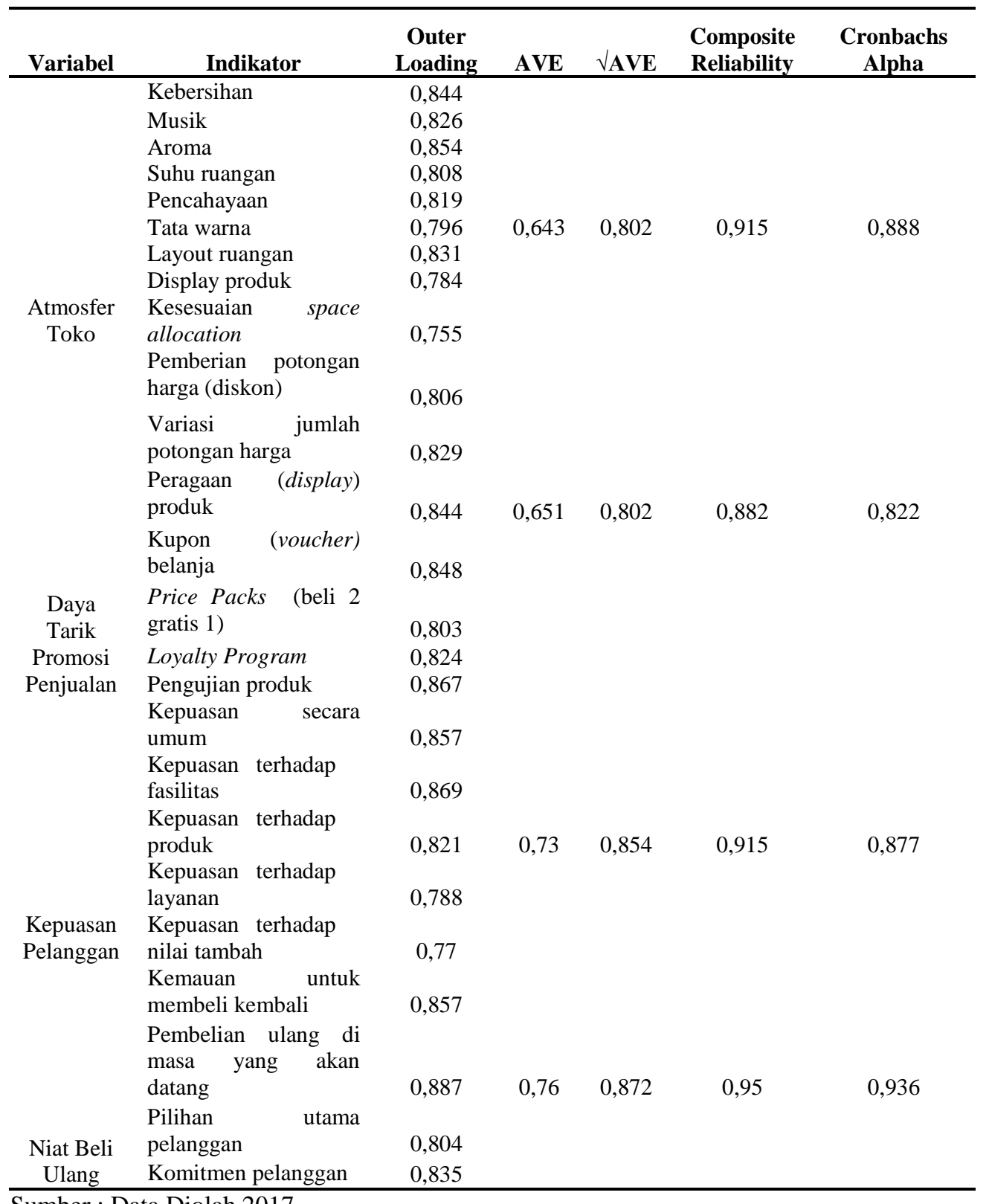

Sumber : Data Diolah 2017

Variabel daya tarik promosi penjualan membuktikan bahwa pemberian potongan harga (diskon), variasi jumlah potongan harga, peragaan (display) produk, kupon (voucher) belanja, price packs (beli 2 gratis 1), layout program dan pengujian produk mempunyai outer loading lebih besar dari 0.5. Indikator 
I Putu Gede Manik Kartika Yudha., Ni Wayan Sri Suprapti. Pengaruh Atmosfer Toko...

pengujian produk adalahindikator terkuat dari variabel daya tarik promosi penjualan karena memiliki outer loading paling besar $(0,867)$. Variabel kepuasan pelanggan membuktikan bahwa kepuasan secara umum, kepuasan terhadap fasilitas, kepuasan terhadap produk, kepuasan terhadap layanan dan kepuasan terhadap nilai tambah memiliki outer loading lebih besar dari 0.5. Indikator kepuasan terhadap fasilitas merupakan indikator terkuat dari variabel kepuasan pelanggan karena mempunyai outer loading paling besar (0,869). Variabel niat beli ulang membuktikan bahwa kemauan untuk membeli kembali, pembelian ulang di masa yang akan datang, pilihan utama pelanggan dan komitmen pelanggan mempunyai outer loading lebih besar dari 0.5 . Indikator pembelian ulang di masa yang akan datang merupakan indikator terkuat dari variabel niat beli ulang karena memiliki nilai outer loading paling besar $(0,887)$.

Tabel 3 menunjukkan bahwa nilai AVE seluruh konstruk >0,50, namun rata-rata seluruh nilai $\sqrt{ }$ AVE antara 0,802 hingga 0,872 lebih kecil dari korelasi antar konstruk yaitu antara 0,812 sampai dengan 0,882, sehingga dari kriteria nilai AVE memenuhi syarat valid berdasarkan kriteria discriminant validity, namun tidak valid dari segi perbandingan antara akar AVE dengan korelasi antar konstruk.

Tabel 3 menunjukkan bahwa nilai composite reliability dan Cronbach Alpha seluruh konstruk telah menunjukkan nilai lebih besar dari 0.70 , sehingga memenuhi syarat reliable berdasarkan kriteria composite reliability. 
Berdasarkan dari hasil evaluasi secara keseluruhan, baik convergent validity, discriminant validity, composite reliability, yang telah dipaparkan diatas, maka dapat dijelaskan bahwa indikator-indikator sebagai pengukur variable laten merupakan pengukur yang valid dan reliabel.

Tabel 4

Evaluasi Model Struktural Inner

\begin{tabular}{lc}
\hline Konstruk & R Square \\
\hline Kepuasan Pelanggan & 0,765 \\
Niat Beli Ulang & 0,772 \\
\hline Sumber : Data Diolah, 2017 & \\
\multicolumn{1}{c}{ Pengujian inner model dilakukan dengan melihat nilai R-square }
\end{tabular}
yang merupakan uji goodness of fit model. Tabel 4 menunjukkan bahwa nilai $\mathrm{R}^{2}$ Kepuasan sebesar 0,765 ; berdasarkan kriteria Chin (Lathan dan Ghozali, 2012), maka model tersebut termasuk kriteria model kuat, maknanya adalah variasi Atmosfer Toko dan Daya Tarik Promosi Penjualan mampu menjelaskan Kepuasan Pelanggan sebesar 76,5 persen, sisanya 23,5 persen dijelaskan oleh variasi variabel lain. Dengan demikan Niat Beli Ulang memiliki nilai $R$-square sebesar 0,772 atau termasuk model kuat, artinya variasi Atmosfer Toko, Daya Tarik Promosi Penjualan dan Kepuasan Pelanggan mampu menjelaskan variasi Niat Beli Ulang yaitu sebesar 77,2 persen sisanya 22,8 persen dijelaskan oleh variasi konstruk lain diluar model.

Berdasarkan Tabel 5, hasil pengujian terhadap koefisien parameter antara atmosfer toko terhadap kepuasan pelanggan menunjukkan adanya hubungan yang positif dengan nilai koefisien sebesar 0,312 dengan nilai 
I Putu Gede Manik Kartika Yudha., Ni Wayan Sri Suprapti. Pengaruh Atmosfer Toko...

t-statistik sebesar 3,393. Nilai t-statistik tersebut berada diatas nilai kritis 1,96, maka atmosfer toko berpengaruh secara positif dan signifikan terhadap kepuasan pelanggan.

\section{Tabel 5 \\ Result For Inner Weights}

\begin{tabular}{lccccc}
\hline & $\begin{array}{l}\text { Original } \\
\text { Sample } \\
(\mathrm{O})\end{array}$ & $\begin{array}{l}\text { Sample } \\
\text { Mean } \\
(\mathrm{M})\end{array}$ & $\begin{array}{l}\text { Standard } \\
\text { Deviation } \\
\text { (STDEV) }\end{array}$ & $\begin{array}{l}\text { t Statistics } \\
(|\mathrm{O} / \mathrm{STERR}|)\end{array}$ & Kesimpulan \\
\hline $\begin{array}{l}\text { Konstruk } \\
\text { ATMOSFER -> }\end{array}$ & 0,312 & 0,315 & 0,133 & 3,393 & Diterima \\
$\begin{array}{l}\text { KEPUASAN } \\
\text { ATMOSFER -> }\end{array}$ & 0,556 & 0,537 & 0,23 & 4,651 & Diterima \\
$\begin{array}{l}\text { NIATBELI } \\
\text { PROMOSI -> }\end{array}$ & 0,583 & 0,582 & 0,077 & 6,349 & Diterima \\
$\begin{array}{l}\text { KEPUASAN } \\
\text { PROMOSI -> }\end{array}$ & 0,316 & 0,316 & 0,346 & 4,557 & Diterima \\
$\begin{array}{l}\text { NIATBELI } \\
\text { KEPUASAN -> } \\
\text { NIATBELI }\end{array}$ & 0,455 & 0,46 & 0,088 & 4,053 & Diterima \\
\hline SIATH
\end{tabular}

Sumber : Data Diolah, 2017

Hasil uji terhadap koefisien parameter antara atmosfer toko terhadap niat beli ulang menunjukkan adanya hubungan yang positif dengan nilai koefisien sebesar 0,556 dengan nilai t-statistik sebesar 4,651. Nilai tstatistik tersebut berada diatas nilai kritis 1,96 , maka atmosfer toko berpengaruh secara positif dan signifikan terhadap niat beli ulang. Hasil uji terhadap koefisien parameter antara daya tarik promosi penjualan terhadap kepuasan pelanggan menunjukkan adanya hubungan yang positif dengan nilai koefisien sebesar 0,583 dengannilai t-statistik sebesar 6,349. Nilai t-statistik tersebut berada pada diatas nilaikritis 1,96, maka daya tarik promosi penjualan berpengaruh secara positif dan signifikan terhadap kepuasan pelanggan. Hasil uji terhadap koefisien parameter antara 
daya tarik promosi penjualan terhadap niat beli ulang menunjukkan adanya hubungan yang positif dengan nilai koefisien sebesar 0,316 dengan nilai tstatistik sebesar 4,557. Nilai t-statistik tersebut berada pada diatas nilai kritis 1,96, maka promosi penjualan berpengaruh secara positif dan signifikan terhadap niat beli ulang. Hasil uji terhadap koefisien parameter antara kepuasan pelanggan terhadap niat beli ulang menunjukkan adanya hubungan yang positif dengan nilai koefisien sebesar 0,455 dengan nilai t-statistik sebesar 4,053. Nilait-statistik tersebut berada pada diatas nilai kritis 1,96, maka kepuasan pelanggan berpengaruh secara positif dan signifikan terhadap niat beli ulang.

Hasil penelitian menunjukkan bahwa atmosfir toko berpengaruh positif terhadap kepuasan pelanggan, artinya hasil ini sesuai dengan penelitian yang dilakukan oleh Wandira (2016), Sihombing dan Lestari (2013) yang mengatakan bahwa atmosfer toko berpengaruh positif terhadap kepuasan pelanggan.

Hasil penelitian menunjukkan bahwa atmosfer toko berpengaruh positif terhadap niat beli ulang, artinya hasil ini sesuai dengan penelitian yang dilakukan oleh Wandira (2016) dan Alma (2009) yang mengatakan bahwa atmosfer toko berpengaruh posistif terhadap niat beli ulang pelanggan.

Hasil penelitian menunjukkan bahwa daya tarik promosi penjualan berpengaruh posistif terhadap kepuasan pelanggan, artinya hasil inisesuai dengan penelitian yang dilakukan oleh Diyanthini dan Seminari (2014) 
I Putu Gede Manik Kartika Yudha., Ni Wayan Sri Suprapti. Pengaruh Atmosfer Toko...

dan juga Alma (2009) promosi penjualan berpengaruh posistif terhadap kepuasan pelanggan.

Hasil penelitian menunjukkan bahwa daya tarik promosi penjualan berpengaruh positif terhadap niat beli ulang, artinya hasil ini sesuaidengan penelitian yang dilakukan oleh Prasetyo (2013), Amanda dan Mudiantono (2015) menunjukkan bahwa promosi penjualan berpengaruh secara positif dan signifikan terhadap niat beli.

Hasil penelitian menunjukkan bahwa kepuasan pelanggan berpengaruh posistif terhadap niat beli ulang, hasil ini sesuai dengan penelitian yang dilakukan oleh Asakdiyah (2005), Saidani dan Arifin (2012) yang menemukan bahwa kepuasan pelanggan berpengaruh positif terhadap niat beli ulang pelanggan.

\section{IMPLIKASI PENELITIAN}

Pada penelitian ini ditemukan hasil bahwa atmosfer toko berpengaruh positif dan signifikan terhadap kepuasan pelanggan dan niat beli ulang. Begitu pula daya tarik promosi penjualan berpengaruh positif dan signifikan terhadap kepuasan dan niat beli ulang pelanggan.

Temuan dalam penelitian ini memperkaya bukti empiris hubungan atmosfer toko dan daya tarik promosi penjualan terhadap kepuasan pelanggan serta pengaruh atmosfer toko, daya tarik promosi penjualan dan kepuasan pelanggan terhadap niat beli ulang. Hasil penelitian ini mendukung hasil studi bahwa ketika pelanggan merasakan afmosfer toko kondusif serta daya tarik promosi 
penjualan yang menarik, maka pelanggan akan merasa puas sehingga akan mengakibatkan tingginya niat beli ulang pelanggan.

Semakin baik atmosfer toko yang ada di Matahari Mall Bali Galeria maka semakin tinggi pula kepuasan dan niat beli ulang pelanggan. Begitu pula daya tarik promosi penjualan, semakin tinggi daya tarik promosi penjualan yang dilakukan oleh Matahari Mall Bali Galeria, maka semakin tinggi pula kepuasan dan niat beli ulang pelanggan.

\section{SIMPULAN DAN SARAN}

Berdasarkan hasil analisis penelitian yang telah dilakukan, dapatditarik beberapa kesimpulan yaitu :

1) Atmosfer toko berpengaruh secara positif dan signifikan terhadap kepuasan pelanggan yang artinya bahwa, semakin baik atmosfer toko yang ada di Matahari Mall Bali Galeria, maka semakin tinggi tingkat kepuasan pelanggan Matahari Mall Bali Galeria.

2) Daya tarik promosi penjualan berpengaruh secara positif dan signifikan terhadap kepuasan pelanggan yang artinya bahwa semakin menarik promosi yang dilakukan oleh Matahari Mall Bali Galeria, maka semakin tinggi pula kepuasan pelanggan Matahari Mall Bali Galeria.

3) Kepuasan pelanggan berpengaruh secara positif dan signifikan terhadap niat beli ulang yang artinya semakin tinggi kepuasan pelanggan Matahari Mall Bali Galeria, maka semakin tinggi pula niat beli ulang yang dilakukan oleh pelanggan Matahari Mall Bali Galeria. 
I Putu Gede Manik Kartika Yudha., Ni Wayan Sri Suprapti. Pengaruh Atmosfer Toko...

4) Atmosfer toko berpengaruh secara positif dan signifikan terhadap niat beli ulang yang artinya bahwa, semakin baik atmosfer toko yang ada di Matahari Mall Bali Galeria maka semakin tinggi niat beli ulang pelanggan.

5) Daya tarik promosi penjualan berpengaruh secara positif dan signifikan terhadap niat beli ulang, yang artinya bahwa semakin menarik daya tarik promosi penjualan yang dilakukan oleh Matahari Mall Bali Galeria, maka semakin tinggi niat beli ulang pelanggan.

Berdasarkan hasil penelitian ada beberapa saran yang dapat penulis ajukan, yaitu:

1) Manajemen Matahari Mall Bali Galeria disarankan untuk semakin meningkatkan atmosfer toko, sehingga semakin meningkatkan kepuasan pelanggan dan pada gilirannnya akan lebih meningkatkan niat beli ulang pelanggan.

2) Manajemen Matahari Mall Bali Galeria hendaknya lebih memperhatikan tata warna dalam toko agar menjadi lebih baik lagi dengan mengganti kombinasi warna ruangan dengan warna-warna menarik, penyusunan display produk yang kreatif agar terlihat lebih menarik di mata pelanggan, dan kesesuaian space allocation secukupnya agar tidak terlalu sempit sehingga memudahkan pergerakan pelanggan saat berbelanja. 


\section{REFERENSI}

Ailawadi, K. L., and Neslin, S. A. 1998. The Effect of Promotion on Consumption: Buying More and Consuming it Faster. Journal of Marketing Research. Vol. 35, pp.390-398.

Alimpic, S. 2014. The Effectiveness Of Sales Promotion Tools: Customers' Perspective. Actual Problems Of Economiics \#12((162)).

Alma, B. 2009. Manajemen Pemasaran dan Pemasaran Jasa. Bandung: Alfabeta.

Amanda, L. dan Mudiantono. 2015. Analisis Pengaruh Celebrity Endorser Dan Promosi Penjualan Terhadap Keunggulan Merek Serta Pengaruhnya Terhadap Minat Beli Sepeda Motor Yamaha Mio (Studi Kasus Pada Warga Di Kota Semarang). Diponegoro Journal of Management. Volume 4, Nomor 3. Halaman 1-12

Anderson, Eugene W., Claes Fornell, and Sanal K. Mazvancheryl. 2004. Customer Satisfaction and Shareholder Value. Journal of Marketing. 68 (October), 172-85.

Asakdiyah, S. 2005, Analisis Hubungan Antara Kualitas Pelayanan dan Kepuasan Pelanggan dalam Pembentukan Intensi PembelianKonsumen Matahari Group di Daerah Istimewa Yogyakarta, Jurnal Akuntansi dan Manajemen.Vol. XVI No.2, hal. 133-157

Baker, J., Grewal, D. and Parasuraman, A. 1994. The influence of store environment on quality inferences and store image. Journal of Academic of Marketing Science. Vol. 22 No. 4, pp. 328-339.

Boddewyn, J. J., and Leardi, M. 1989. Sales Promotion Practice, Regulation and Self-Regulation Around the World. International Journal of Advertising. Vol. 8 No. 4, p.363.

Carpenter, J. M., dan Fairhurst, A. 2005. Consumer shopping value, satisfaction, and loyalty for retail apparel brands. Journal of Fashion Marketing and Management: An International Journal, Vol. 9 Issue: 3, pp.256-269,

Diyanthini, N. P. D. dan Seminari, N. K. 2014. Pengaruh Citra Perusahaan, Promosi Penjualan dan Kualitas Pelayanan Terhadap Kepuasan Nasabah Pada LPD Desa Pakraman Panjer. E-Jurnal Manajemen Universitas Udayana, [S.1.], v. 3, n. 10, oct. 2014. ISSN 2302-8912

Donovan, R. J., Rossister, J. R., Marcoolyn, G., Nesdale, A. 1994. Store Atmosphere and Purchasing Behavior. Journal of Retailing. Vol. 70, No. 3, pp. 283-294. 
I Putu Gede Manik Kartika Yudha., Ni Wayan Sri Suprapti. Pengaruh Atmosfer Toko...

Eroglu, S.A. and Machleit, K.A. 1990. An empirical study of retail crowding: antecedents and consequences. Journal of Retailing. Vol. 66 No. 2, pp. 201-221.

Gardner, M.P. and Siomkos, G.J. 1985. Toward a methodology for assessing effects of in-store atmospherics. Advances Consumer Research. Vol. 13 No. 1, pp. 27-31.

Giese, J.L., Cote, J.A. 2000. Defining Customer Satisfaction. Academy of Marketing Science Review. Vol. 2000, No. 1

Grewal, D., Baker, J., Levy, M. and Voss, G.B. 2003. The effects of wait expectations and store atmosphere evaluations on patronage intentions in service-intensive retail stores. Journal of Retailing. Vol. 79 No. 4, pp. 259268.

Hanssens, D.M., Parsons, L.J., and Schultz, R.L. 2001. Market Response Models: Econometric and Time Series Analysis. second ed. Kluwer Academic Publishers. Dordrecht.

Hellier, P.K., Geursen, G.M., Carr, R.A. dan Rickard, J.A. 2003. Customer Repurchase Intention. A General Structural Equation Model, European Journal of Marketing, Vol. 37 No. 11/12, pp. 1762-1800.

Hersanti, N. J., dan Ratnawati, K. 2012. Pengaruh Atmosfer Terhadap Kepuasan dan Niatan Perilaku Konsumen di Toko "Oen" Kota Malang. Jurnal Aplikasi Manajemen.Volume 10 Nomor 4.

Johnson, M.D., Anderson, E.W., Fornell, C. 1995. Rational and adaptive performance expectations in a customer satisfaction framework. Journal of Consumer Research. Vol. 21, No. 4, pp. 695-707.

Karmela, L. dan Junaedi, J. 2009. Pengaruh Store Atmosphere terhadap Minat Beli Kosumen pada Toserba Griya Kuningan. Jakarta: Equilibrium, 5(9).

Khan, S., Hussain, S. M., dan Yaqoob, F. 2012. Determinants of Customer Satisfaction in Fast Food Industry, International Journal of Management and Strategy. Vol. 3.

Kotler, P., dan Keller, K.L. 2009. Manajemen Pemasaran Jilid 1, edisi Ketiga Belas, Terjemahan Bob Sabran, MM. Jakarta: Penerbit Erlangga.

Levy, M. dan Weitz, B. A. 2004. Retailing Management. USA: Richard D Irwin, Inc. 
Neha, S., dan Manoj,.V. 2013. Impact of Sales Promotion Tools on Consumer's Purchase Decision towards White Good (Refrigerator) at Durg and Bhilai Region of CG, India. Research Journal of Management Sciences, ISSN 2319-1171, Vol. 2(7), 10-14, Res. J. Management Sci.

Nizar, S, D., Andriani, A., dan Kholid., M, M. 2016. The Influence Of Store Atmosphere On Purchase Decision And It's Impact On Customer's Satisfaction (Case study on Indomaret Customers JL. Raya Tlogomas No. 37, Malang). Jurnal Administrasi Bisnis (JAB).Vol. 30 No. 1.

Pudjianto, Michelle, G., Cecilia, A. S., dan Marcus, R. "Pengaruh Store Atmosphere Terhadap Customer Satisfaction Di Domicile Kitchen And Lounge Surabaya." Jurnal Hospitality dan Manajemen Jasa 4.2 (2016): 399-410.

Rust, R. T. \& Zahorik, A. J. 1993. Customer Satisfaction, Customer Retention, and Market share. J. Retailing. 69. PP.193-215.

Saidani, B. dan Arifin, S. 2012. Pengaruh Kualitas Produk Dan Kualitas Layanan Terhadap Kepuasan Konsumen Dan Minat Beli Pada Ranch Market. Jurnal Riset Manajemen Sains Indonesia (JRMSI) |Vol. 3, No. 1.

Sivadas, E., dan Baker-Prewitt, J, L., 2000. An examination of the relationship between service quality, customer satisfaction, and store loyalty. International Journal of Retail \& Distribution Management. Volume 28 . Number 2 . pp. $73 \pm 82$

Tjahjaningsih, E. 2013. Pengaruh Citra Dan Promosi Terhadap Kepuasan Pelanggan Serta Dampaknya Terhadap Loyalitas Pelanggan (Studi Pada Pelanggan Supermarket Carrefour Di Semarang). Media Ekonomi Dan Manajemen. Vol 28. No 2

Tjiptono, F. 2008. Strategi Pemasaran, Edisi 3, ANDI: Yogyakarta.

Tsai, Hsien-Tung., Huang, Heng-Chiang., Jaw, Yi-Long., dan Chen, Wen-Kuo. 2006. Why on-line customers remain with a particular e-retailer: An integrative model and empirical evidence. Psychology \& Marketing. 23, 5 , pp. 447- 464.

Varga, A., Vujicic, M., dan Dlacic, J. 2014. Repurchase Intentions In A Retail Store - Exploring The Impact Of Colours. Ekonomski Vjesnik / Econviews. God. XXVII, BR. 2/2014. str. 229-244

Wandira, K. R. dan Nugroho, D.A. 2016. Pengaruh Suasana Toko dan Pengaruh Sosial Terhadap Minat Pembelian Ulang Pelanggan Pada Lai-Lai Market 
I Putu Gede Manik Kartika Yudha., Ni Wayan Sri Suprapti. Pengaruh Atmosfer Toko...

Buah dan Sayur dengan Kepuasan Pelanggan sebagai Variabel Intervening. Jurnal Ilmiah Mahasiswa FEB 3 (2). Universitas Brawijaya.

Ward, P., Davies, B.J. and Kooijman, D. 2007. Olfaction and the retail environment: examining the influence of ambient scent. Service Business. Vol. 1 No. 4, pp. 295-316. 